\title{
Dual-Band Operation of a Circularly Polarized Four-Arm Curl Antenna with Asymmetric Arm Length
}

\author{
Son Xuat Ta and Ikmo Park \\ Department of Electrical and Computer Engineering, Ajou University, 5 Woncheon-dong, Yeongtong-gu, \\ Suwon 443-749, Republic of Korea \\ Correspondence should be addressed to Ikmo Park; ipark@ajou.ac.kr
}

Received 20 September 2015; Accepted 27 December 2015

Academic Editor: Shah N. Burokur

Copyright (C) 2016 S. X. Ta and I. Park. This is an open access article distributed under the Creative Commons Attribution License, which permits unrestricted use, distribution, and reproduction in any medium, provided the original work is properly cited.

This paper presents dual-band operation of a single-feed composite cavity-backed four-arm curl antenna. Dual-band operation is achieved with the presence of the asymmetrical arm structure. A pair of vacant-quarter printed rings is used in the feed structure to produce a good circular polarization $(\mathrm{CP})$ at both bands. The cavity-backed reflector is employed to improve the $\mathrm{CP}$ radiation characteristics in terms of the $3-\mathrm{dB}$ axial ratio beamwidth and broadside gain. The proposed antenna is widely applicable in dualband communication systems that have a small frequency ratio. Examples of such a system are global positioning systems.

\section{Introduction}

Curl antennas, which are formed by short single-arm Archimedean or rectangular spirals, have been developed as small, low-profile, circularly polarized $(\mathrm{CP})$ radiation elements [1-12]. Antennas of this kind are mechanically simple and produce $\mathrm{CP}$ radiation with a single-feed without the need for an external circuit. A conventional curl antenna, which is placed approximately a quarter-wavelength above a large ground plane, can provide good impedance matching and good $\mathrm{CP}$ radiation over a bandwidth of approximately $10 \%$ [1-8]. However, these antennas have several drawbacks, such as a slight tilt in the broadside radiation pattern due to their single-arm configuration, the need for a large ground plane, and their limitation to single-band operation. Recently, single-feed four-arm curl antennas have been reported for $\mathrm{CP}$ radiation to improve the performance of conventional curl antennas $[13,14]$. These curl antennas yield single-band CP operation with the same arm length. A dual-band operation can be achieved by dividing the antenna's arms into two branches of different lengths [15]. However, this approach leads to very complicated antenna configuration in the design process.

This paper describes a simple method to design dualband operation of a four-arm curl antenna. Dual-band operation is obtained by creating different arm lengths in the four-arm curl structure. The antenna is optimized for global positioning system (GPS) L1 and L2 bands. The resulting antenna was first characterized with the ANSYS HighFrequency Structure Simulator (HFSS) and then confirmed by experiments. The final design, with an overall size of $90 \times$ $90 \times 30 \mathrm{~mm}^{3}\left(0.3681 \lambda_{0} \times 0.3681 \lambda_{0} \times 0.1227 \lambda_{0}\right.$ at the GPS L2 frequency), yields $\left|S_{11}\right|<-10 \mathrm{~dB}$ bandwidths of 1.217$1.234 \mathrm{GHz}$ and $1.495-1.595 \mathrm{GHz}$ and $\mathrm{AR}<3 \mathrm{~dB}$ bandwidths of $1.220-1.230 \mathrm{GHz}$ and $1.565-1.600 \mathrm{GHz}$. Additionally, the antenna radiates a wide-beam right-hand circular polarization (RHCP) with high radiation efficiency at both bands. In comparison with the dual-band multiarm curl GPS antenna [15], the proposed antenna has a much simpler structure, smaller size, and comparable $\left|S_{11}\right|$ and AR bandwidths.

\section{Antenna Geometry}

Figure 1 shows the geometry of the proposed antenna that is composed of a four-arm curl radiator, a coaxial line, and a reflector. The curl radiator, which is a four-arm Archimedean spiral antenna with a small number of turns, was built on both sides of a circular Rogers $\mathrm{RO} 4003$ substrate with a radius of $R_{\text {sub }}$, a relative permittivity of 3.38, a loss tangent of 0.0027 , and a thickness of $h_{s}$. Two arms (orange color) were placed on the top of the substrate whereas the other two arms (grey 


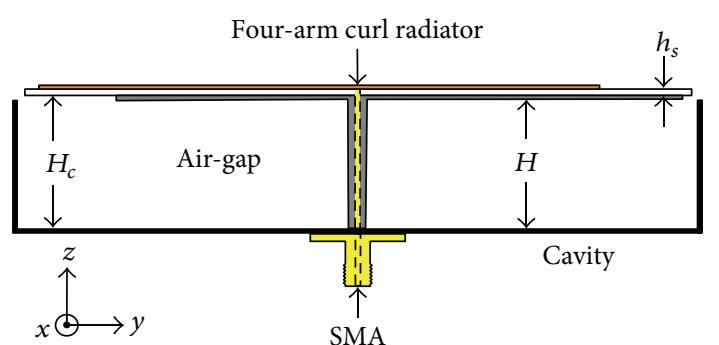

(a)



(b)

FIGURE 1: Geometry of the proposed antenna: (a) cross-sectional view with the cavity-backed reflector and (b) top view of radiator.

color) were on the bottom of the substrate. The curl arm was characterized by the Archimedean spiral drawing function of the HFSS software [16], which is defined by a center position of $(0,0,0)$, a direction vector $(0,0,1)$, a starting point of $R_{0}$, a radius change of $R_{c}$, a number of turns of $n_{i}(i=1,2,3,4)$, and a stripline width of $W_{s}$. The radiator is fed by a vacantquarter printed ring, which helps the antenna to be directly matched to a $50 \Omega$ coaxial line over a broad bandwidth and produces the $\mathrm{CP}$ radiation. The reflector is a rectangular box with base dimensions of $W \times W$ and a height of $H_{c}$. To achieve the dual-band operation, the asymmetrical curl arm structure was created by choosing a different number of turns $\left(n_{i}\right)$ for different arms.

\section{Mechanism of Dual-Band Operation}

As mentioned above, the dual-band operation of the proposed antenna is obtained by choosing a different number of turns for different arms. To demonstrate this, the input impedances $\left(Z_{11}\right)$ of an ideal four-arm curl antenna [13] are examined for symmetric and asymmetric configurations via the HFSS simulation. Figure 2 shows the HFSS simulation


(b)

FIGURE 2: HFSS simulation modeling for an ideal four-arm curl antenna in free space: (a) top view and (b) side view.

modeling of the ideal four-arm curl antenna. The arms were placed on both sides of a $40 \mathrm{~mm}$ radius Rogers $\mathrm{RO} 4003$ substrate with a thickness of $0.508 \mathrm{~mm}$. The orange arms (\#1 and \#3) were on the top of the substrate and the grey arms (\#2 and \#4) were on the bottom of the substrate. Referring to Figure 1(b), the arm was formed by a center position of $(0$, $0,0)$, a direction vector $(0,0,1), R_{0}=9 \mathrm{~mm}, R_{c}=25 \mathrm{~mm}$, $n=1$, and $W_{s}=3 \mathrm{~mm}$. The antenna was simulated by assuming two excitation sources (port-1 for the orange arms and port-2 for the grey arms) and their input impedances $\left(Z_{11}\right.$ or $\left.Z_{22}\right)$ were calculated for three configurations. Case \#1: $n_{1}=n_{2}=n_{3}=n_{4}=1$, case $\# 2: n_{1}=n_{2}=0.9$ and $n_{3}=n_{4}=1$, and case \#3: $n_{1}=n_{2}=1.1$ and $n_{3}=n_{4}=1$. The results were given in Figures 3-5. Since the $Z_{11}$ value is the same as $Z_{22}$ and expresses the input impedance of the ideal four-arm curl antenna, and Figures 3-5 only show the real and imaginary parts of $Z_{11}$ values for the three cases.

As shown in Figure 3, the symmetrical four-arm curl antenna behaves as a resonant antenna in the low-frequency range, whereas the antenna behaves as a traveling wave antenna in the high-frequency region with an almost stable input impedance value. The resonance was defined as the frequency at which the imaginary value of $Z_{11}$ is zero. With the chosen parameters, the antenna yielded two resonances in the interest frequency range. The first one was $1.58 \mathrm{GHz}$ with an input resistance of approximately $50 \Omega$ while the second was $1.79 \mathrm{GHz}$ with an input resistance of approximately 


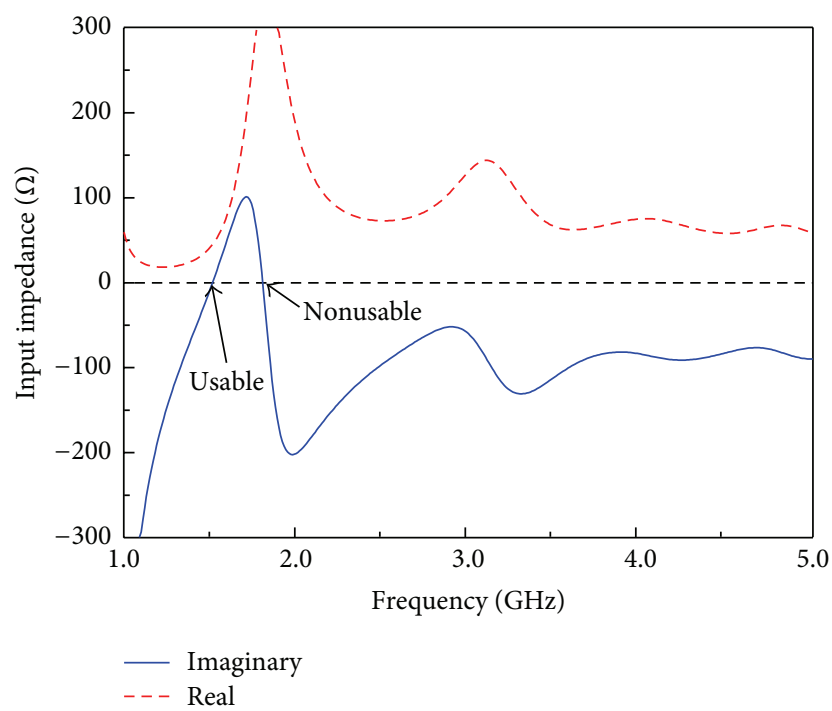

Figure 3: Simulated input impedance $\left(Z_{11}\right.$ or $\left.Z_{22}\right)$ of the ideal symmetrical four-arm curl antenna $\left(n_{1}=n_{2}=n_{3}=n_{4}=1\right)$.

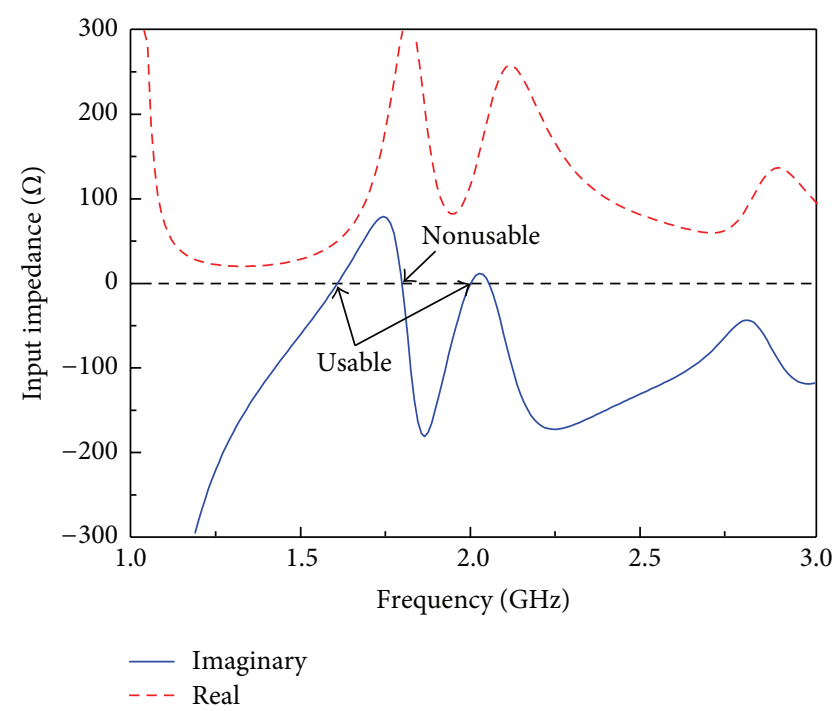

Figure 4: Simulated input impedance $\left(Z_{11}\right.$ or $\left.Z_{22}\right)$ of the ideal asymmetrical four-arm curl antenna $\left(n_{1}=n_{2}=0.9, n_{3}=n_{4}=1\right)$.

$290 \Omega$. In the high-frequency region, the real part of $Z_{11}$ was nearly constant with a value of $60 \Omega$, while the imaginary part of $Z_{11}$ was nearly constant with a value of $-90 \Omega$. For convenience, resonance with $\sim 50 \Omega$ of resistance is called usable resonance, while resonance with a high resistance is called nonusable resonance. This result indicates that the antenna can be well matched to a $50 \Omega$ source without the need for an external circuit at its first resonance.

To create the asymmetrical four-arm curl antennas, the number of turns for arms $\# 1$ and \#2 was varied while the other arms (\#3 and \#4) were fixed. Figure 4 shows the $Z_{11}$ values of an asymmetrical four-arm curl antenna with $n_{1}=n_{2}=0.9$ and $n_{3}=n_{4}=1$. The antenna yielded more resonances compared to the symmetrical one. Two

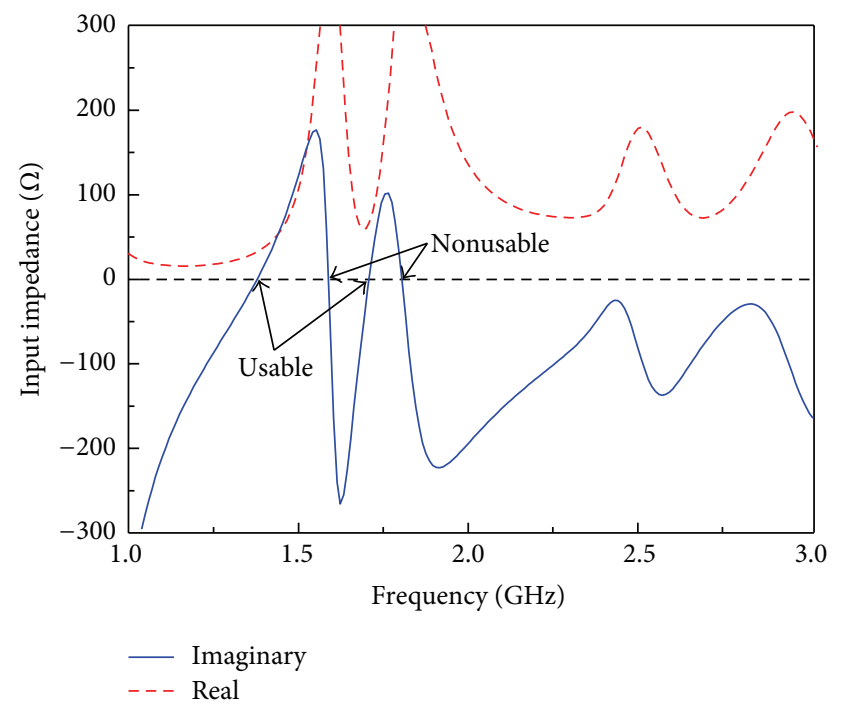

Figure 5: Simulated input impedance $\left(Z_{11}\right.$ or $\left.Z_{22}\right)$ of the ideal asymmetrical four-arm curl antenna $\left(n_{1}=n_{2}=1.1, n_{3}=n_{4}=1\right)$.

resonances at 1.605 and $1.995 \mathrm{GHz}$ can be used because the real values of $Z_{11}$ nearly equal $50 \Omega$. The $Z_{11}$ values of the other asymmetrical curl antenna $\left(n_{1}=n_{2}=1.1\right.$ and $n_{3}=$ $\left.n_{4}=1\right)$ are shown in Figure 5. The antenna yielded two resonances at $1.375 \mathrm{GHz}$ and $1.705 \mathrm{GHz}$ with the real value of $Z_{11}$ approximately $50 \Omega$. These results indicate that both asymmetrical configurations of the four-arm curl antenna yielded a dual-frequency operation in the frequency band of interest. To have a CP wave, the two sources of excitation in Figure 2(b) must have equal amplitudes and a $90^{\circ}$ phase difference. Consequently, the antenna requires a one-to-two power combiner/splitter and a $90^{\circ}$ phase shifter in the feeding structure. This approach complicates the antenna design and fabrication.

To generate the $\mathrm{CP}$ radiation with a single-feed, the asymmetrical four-arm curl antennas are incorporated with a pair of vacant-quarter printed rings, as shown in Figure 6. The rings were designed with a $5.4 \mathrm{~mm}$ radius and a $1 \mathrm{~mm}$ width. Due to the presence of the rings, the antenna geometry was slightly changed compared to the ideal configurations; that is, arms \#1 and \#4 with a number of $n_{t}$ were placed on the top of the substrate whereas arms \#2 and \#3 with a number of $n_{b}$ were placed on the bottom of the substrate. The other design parameters of the antenna were the same as those of the ideal structure in Figure 2. To reconfirm the dual-band operation of the asymmetrical configuration, the $\left|S_{11}\right|$ and AR values of the antenna were calculated for different $n_{t}$ and given in Figure 7. For the symmetrical case $\left(n_{t}=n_{b}=1\right)$, the antenna yielded only the operational band near the GPS L1 frequency. For the asymmetrical case $\left(n_{t}=0.9\right.$ and $\left.n_{b}=1\right)$, the antenna yielded a dual-band operation near $1.7 \mathrm{GHz}$ and $2.1 \mathrm{GHz}$. For the other asymmetrical case $\left(n_{t}=1.1\right.$ and $\left.n_{b}=1\right)$, the antenna yielded a dual-frequency occupied at $1.42 \mathrm{GHz}$ and 1.79 GHz. For both asymmetrical cases, the upper bands were divided by an undesired notch, which could be attributed to the trapping electromagnetic energy between the adjacent 


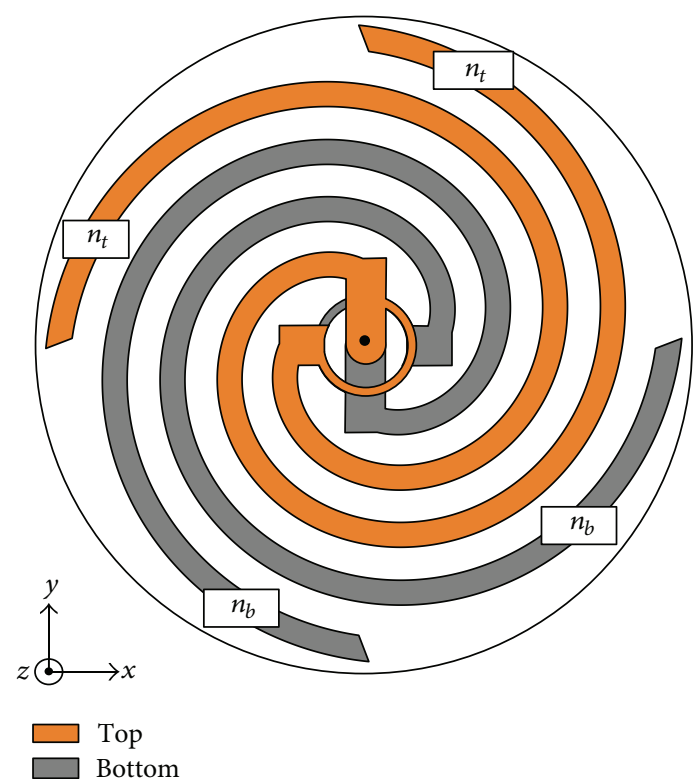

(a)

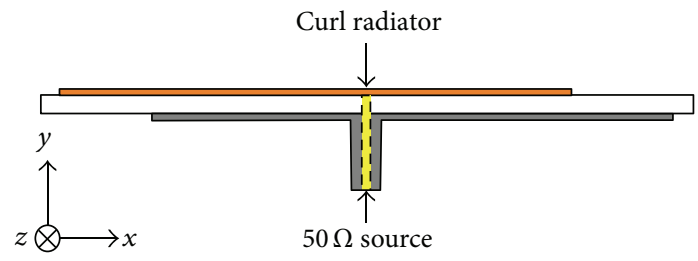

(b)

FIgURE 6: Four-arm curl antenna fed by double vacant-quarter printed rings [8]: (a) top view and (b) side view.

arms. This notch can be eliminated by adjusting the width of the curl arm. Furthermore, the identical behaviors of the dual-band operation were obtained when $n_{t}=1$ is fixed and $n_{b}$ is varied, and, therefore, their results are not shown.

It is well known that the resonances of the curl antenna can be easily controlled by the number of turns, the spacing between turns, and the width of the arm, as well as the dielectric substrate (permittivity and thickness). Also, $\mathrm{CP}$ radiation can easily be achieved by adjusting the ring configurations. Accordingly, the asymmetrical four-arm curl antenna was optimized for good impedance matching and CP radiation at the GPS L1 and L2 frequencies. Note that without the reflector, the four-arm curl antennas radiate a bidirectional electromagnetic wave at their operational frequencies. To achieve a desired broadside pattern at both bands, a cavity-backed reflector with the base dimensions of $90 \times 90 \mathrm{~mm}^{2}\left(0.3681 \lambda_{0} \times 0.3681 \lambda_{0}\right.$ at the GPS L2 frequency or $0.4725 \lambda_{0} \times 0.4725 \lambda_{0}$ at the GPS L1 frequency) and a height of $30 \mathrm{~mm}\left(0.1227 \lambda_{0}\right.$ at the GPS L2 frequency or $0.1575 \lambda_{0}$ at the GPS L1 frequency) was employed in the antenna. Referring to Figure 1(b), the parameters of the final design are as follows: $R_{c}=27 \mathrm{~mm}, R_{0}=9.7 \mathrm{~mm}, R_{r}=6 \mathrm{~mm}$, $W_{r}=1 \mathrm{~mm}, W_{b}=6 \mathrm{~mm}, W_{s}=4.5 \mathrm{~mm}, h_{s}=0.508 \mathrm{~mm}$, $H=30 \mathrm{~mm}, H_{c}=30 \mathrm{~mm}, n_{1}=1.198, n_{2}=1.185$, $n_{3}=1.044$, and $n_{4}=1.035$. To demonstrate the effects



(a)

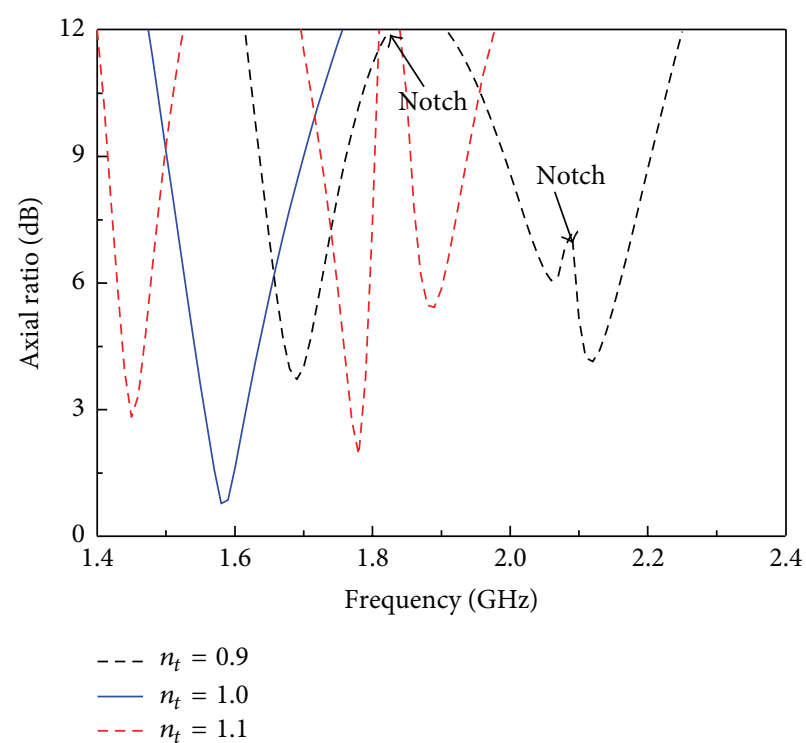

(b)

FigURE 7: Simulated (a) $\left|S_{11}\right|$ and (b) AR values of the four-arm curl antenna shown in Figure 6 for different $n_{t}\left(n_{b}=1\right.$ was fixed).

of the cavity on AR performance, the $\left|S_{11}\right|$ and AR values of the dual-band asymmetrical four-arm curl antenna in different configurations, including those in free space and at different heights of the cavity, were calculated and are shown in Figure 8. The cavity-backed antenna yielded a narrower impedance bandwidth, but significantly better CP performance compared to the case in free space. With an increase of $H_{c}$, the resonance and CP center frequencies of the antenna decreased at both operating frequencies, and the AR characteristic improved significantly. For $H_{c}=30 \mathrm{~mm}$, the simulations resulted in good impedance matching and $\mathrm{CP}$ radiation at both bands. Its impedance bandwidths were $1.220-1.235 \mathrm{GHz}$ and $1.510-1.605 \mathrm{GHz}$ for $\left|S_{11}\right|<-10 \mathrm{~dB}$, and 


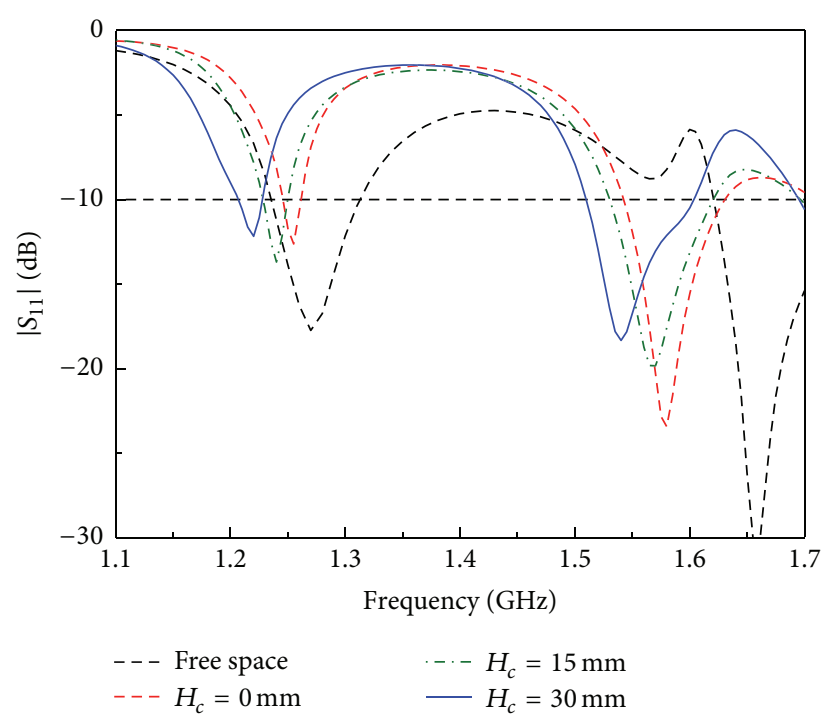

(a)



(b)

FIgURE 8: Simulated (a) $\left|S_{11}\right|$ and (b) AR values of the asymmetrical four-arm curl antenna in different configurations.

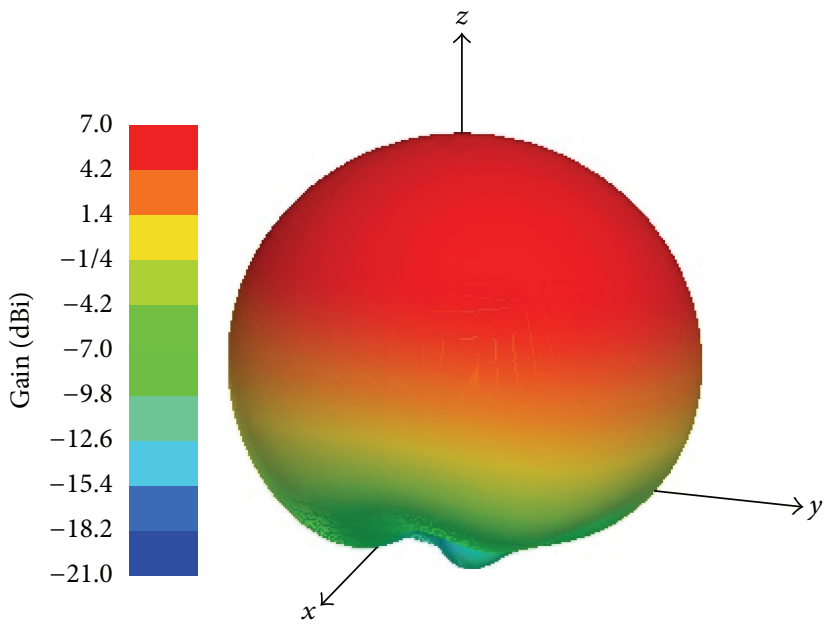

(a)
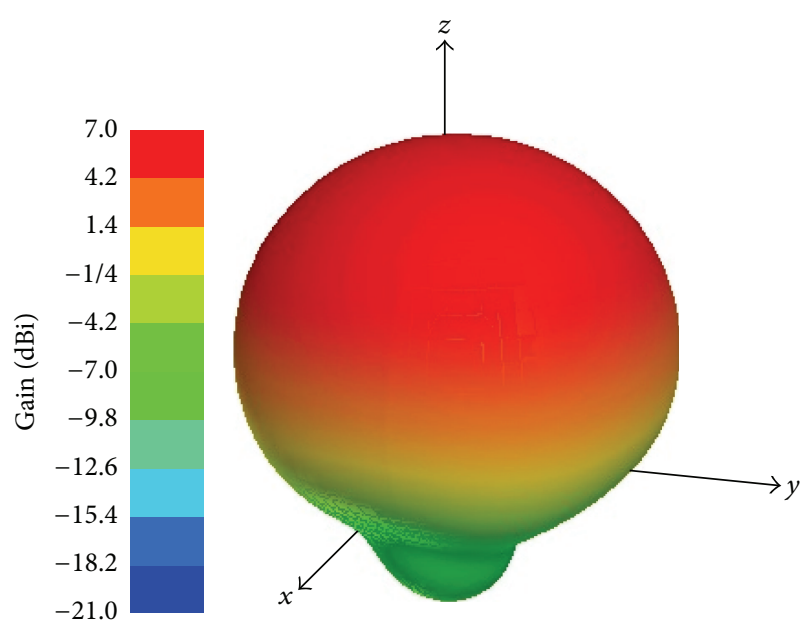

(b)

FIGURE 9: Simulated 3D total-gain pattern of the cavity-backed asymmetrical four-arm curl antenna with $H_{c}=30 \mathrm{~mm}$ : (a) GPS L1 and (b) GPS L2 frequencies.

its 3-dB AR bandwidths were $1.222-1.232 \mathrm{GHz}$ and $1.570-$ $1.605 \mathrm{GHz}$ with two $\mathrm{CP}$ center frequencies at $1.227 \mathrm{GHz}$ $(\mathrm{AR}=0.66 \mathrm{~dB})$ and $1.580 \mathrm{GHz}(\mathrm{AR}=1.13 \mathrm{~dB})$. As shown in Figure 9, the antenna yielded an excellent unidirectional radiation pattern at both bands. The simulations resulted in a gain of $6.9 \mathrm{dBic}$ and a radiation efficiency of $97 \%$ at the GPS L1 frequency but a gain of $6.7 \mathrm{dBic}$ and a radiation efficiency of $91 \%$ at the GPS L2 frequency.

\section{Measurements}

For verification, the dual-band asymmetrical four-arm curl GPS antenna was realized and measured. The radiator was built on both sides of a Rogers RO4003 substrate with a copper thickness of $17 \mu \mathrm{m}$ via a standard wet-etching technology. The reflector was constructed from five copper plates (one $90 \times 90 \mathrm{~mm}^{2}$ and four $90 \times 30 \mathrm{~mm}^{2}$ ) with a thickness of $0.2 \mathrm{~mm}$. Figure 11 shows the measured and simulated $\left|S_{11}\right|$ and AR values of the fabricated prototype (Figure 10). The measurements resulted in a $\left|S_{11}\right|<-10 \mathrm{~dB}$ bandwidth of $1.217-1.234 \mathrm{GHz}$ and $1.495-1.595 \mathrm{GHz}$ and a $3-\mathrm{dB}$ AR bandwidth of $1.220-1.230 \mathrm{GHz}$ and $1.565-1.600 \mathrm{GHz}$ with two $\mathrm{CP}$ center frequencies at $1.225 \mathrm{GHz}(\mathrm{AR}=1.22 \mathrm{~dB})$ and $1.590 \mathrm{GHz}(\mathrm{AR}=0.7 \mathrm{~dB})$, respectively. These measurements agreed quite closely with the HFSS predictions.

Figure 12 shows a comparison of simulated and measured gain patterns for the fabricated antenna at the GPS L1 and L2 frequencies. The measured results are in good agreement with 


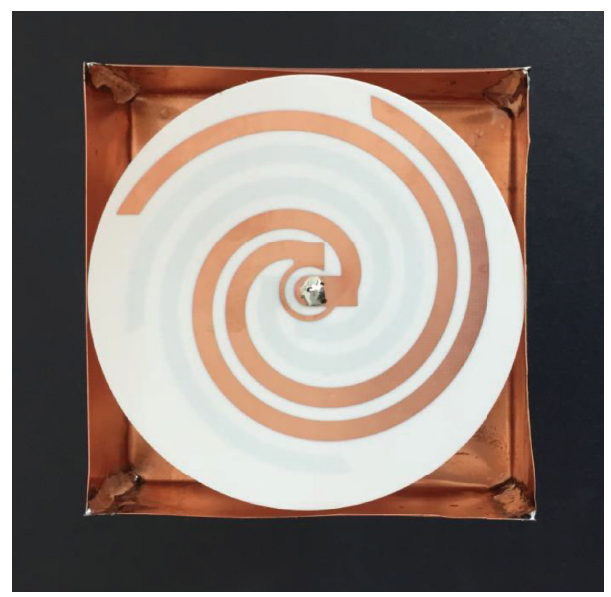

FIgURE 10: Top view of the fabricated dual-band GPS antenna.

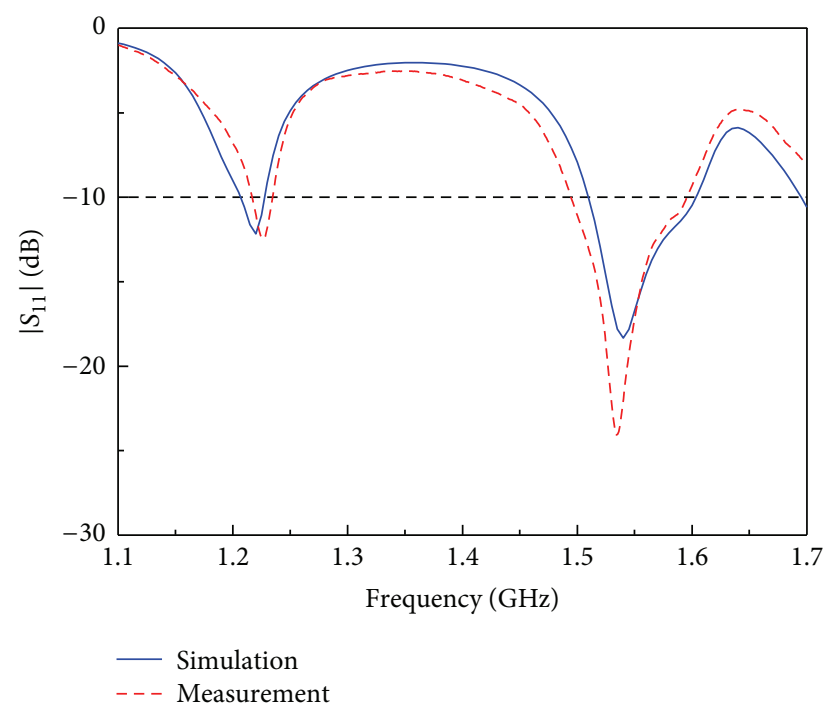

(a)

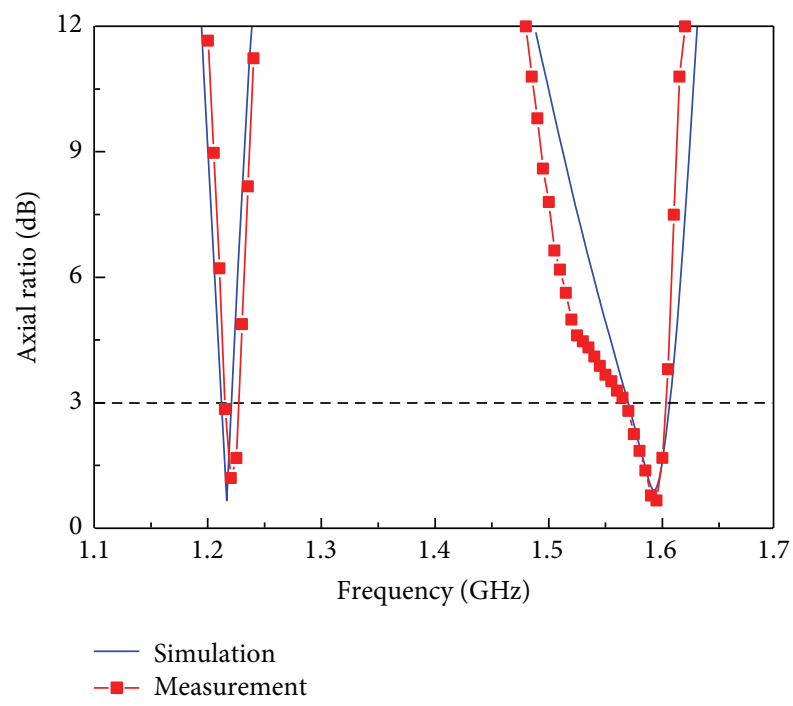

(b)

FIgURE 11: Measured and simulated (a) $\left|S_{11}\right|$ and (b) AR values of the fabricated antenna.

the HFSS simulation. The antenna yielded an RHCP radiation with wide beam and symmetrical profiles at both bands. At the GPS L1 frequency, the measurements resulted in a gain of $7.0 \mathrm{dBic}$, a front-to-back ratio of $18 \mathrm{~dB}$, and half-power beam width (HPBW) of $82^{\circ}$ and $84^{\circ}$ in the $x-z$ and $y$ - $z$ planes, respectively. At the GPS L2 frequency, the antenna yielded a gain of $6.7 \mathrm{dBic}$, a front-to-back ratio of $15 \mathrm{~dB}$, and HPBW of $92^{\circ}$ and $82^{\circ}$ in both $x-z$ and $y-z$ planes, respectively. As shown in Figure 13, both simulations and measurements resulted in a broad 3-dB AR beamwidth $\left(>120^{\circ}\right)$ at two frequencies. Additionally, the measured radiation efficiencies were $95.0 \%$ and $87.0 \%$ at the GPS L1 and L2 frequencies, respectively.

Table 1 shows the comparison of the measured performance of the proposed antenna with that of the dualband multiarm curl GPS antenna [15]. The proposed antenna yielded a simpler configuration, a smaller size, and comparable operational bandwidths. Table 2 shows a comparison of the measured performance of the proposed antenna and those of previous single-feed dual-band GPS antennas [1723]. It is observed that the proposed antenna yielded a significantly wider 3-dB AR beamwidth at both bands as compared to the other antennas.

\section{Conclusion}

A composite cavity-backed four-arm curl antenna has been developed for dual-band operation by creating an asymmetrical arm structure. The antenna with overall dimensions of $90 \times 90 \times 30 \mathrm{~mm}^{3}\left(0.3681 \lambda_{0} \times 0.3681 \lambda_{0} \times 0.1227 \lambda_{0}\right.$ at the GPS L2 frequency) resulted in a $\left|S_{11}\right|<-10 \mathrm{~dB}$ bandwidth of $1.217-$ $1.234 \mathrm{GHz}$ and $1.495-1.595 \mathrm{GHz}$ and a $3-\mathrm{dB}$ AR bandwidth of $1.220-1.230 \mathrm{GHz}$ and $1.565-1.600 \mathrm{GHz}$. Furthermore, the antenna radiates wide-beam $\mathrm{RHCP}\left(>120^{\circ}\right)$ and operates with high radiation efficiency $(>85 \%)$ at both bands. With many advantages, such as compact size, good CP radiation, widebeam, and high radiation efficiency, this antenna is a good 
TABLE 1: Performance comparison of dual-band multiarm curl antennas.

\begin{tabular}{lcccccc}
\hline Antenna structure & Overall size $\left(\mathrm{mm}^{3}\right)$ & Arm number & $\left|S_{11}\right|$ BW $(\mathrm{GHz})$ & AR BW $(\mathrm{GHz})$ & Gain $(\mathrm{dBic})$ & RE $(\%)$ \\
\hline \multirow{2}{*}{ Proposed } & \multirow{2}{*}{$90 \times 90 \times 30$} & \multirow{2}{*}{4} & $1.217-1.234$ & $1.220-1.230$ & 6.0 & 87.0 \\
& & & $1.495-1.595$ & $1.570-1.605$ & 7.0 & 95.0 \\
\hline \multirow{2}{*}{ Ref. [15] } & \multirow{2}{*}{$100 \times 100 \times 30$} & \multirow{2}{*}{8} & $1.221-1.282$ & $1.212-1.240$ & 7.3 & 88.4 \\
& & & $1.545-1.660$ & $1.560-1.590$ & 7.5 & 92.0 \\
\hline
\end{tabular}
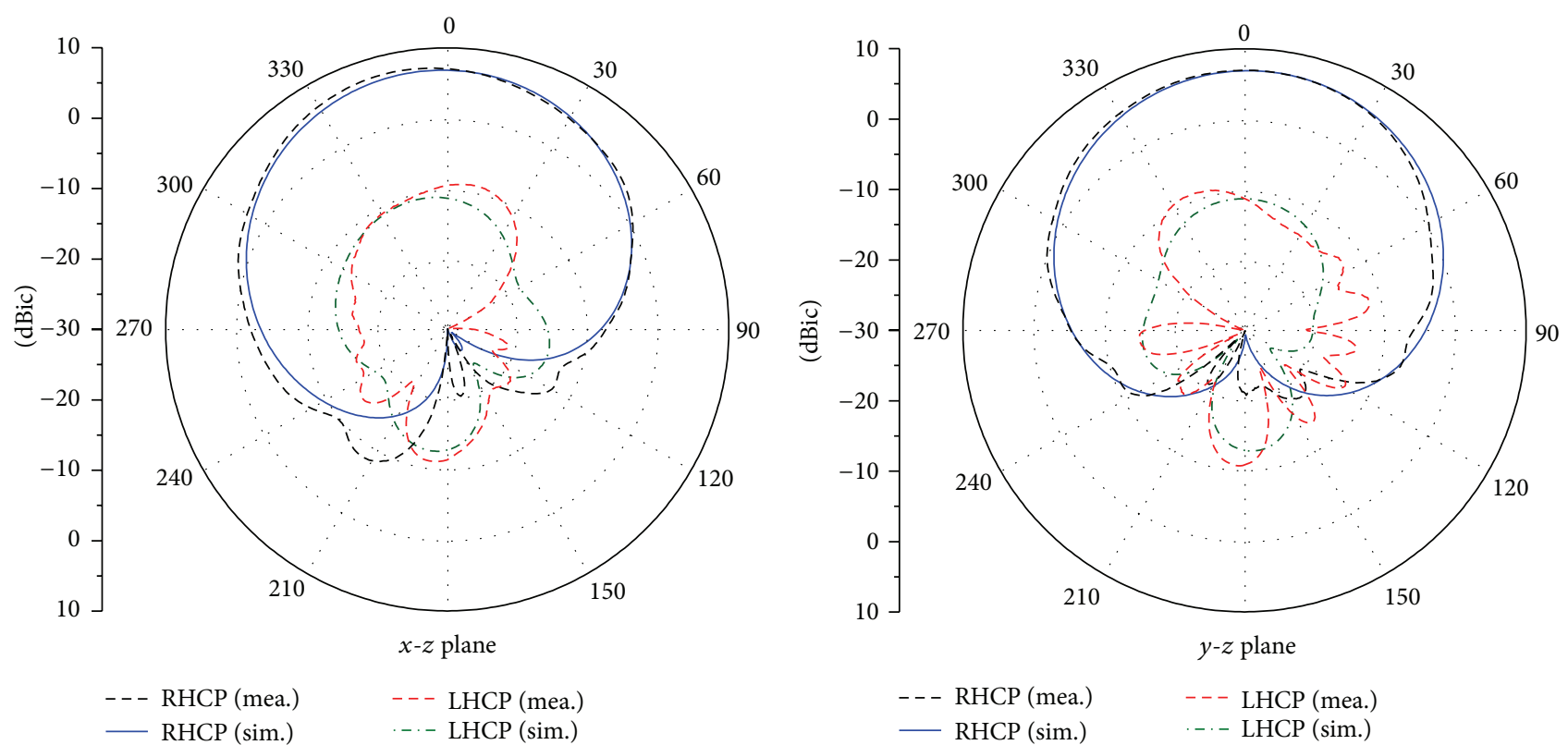

(a)
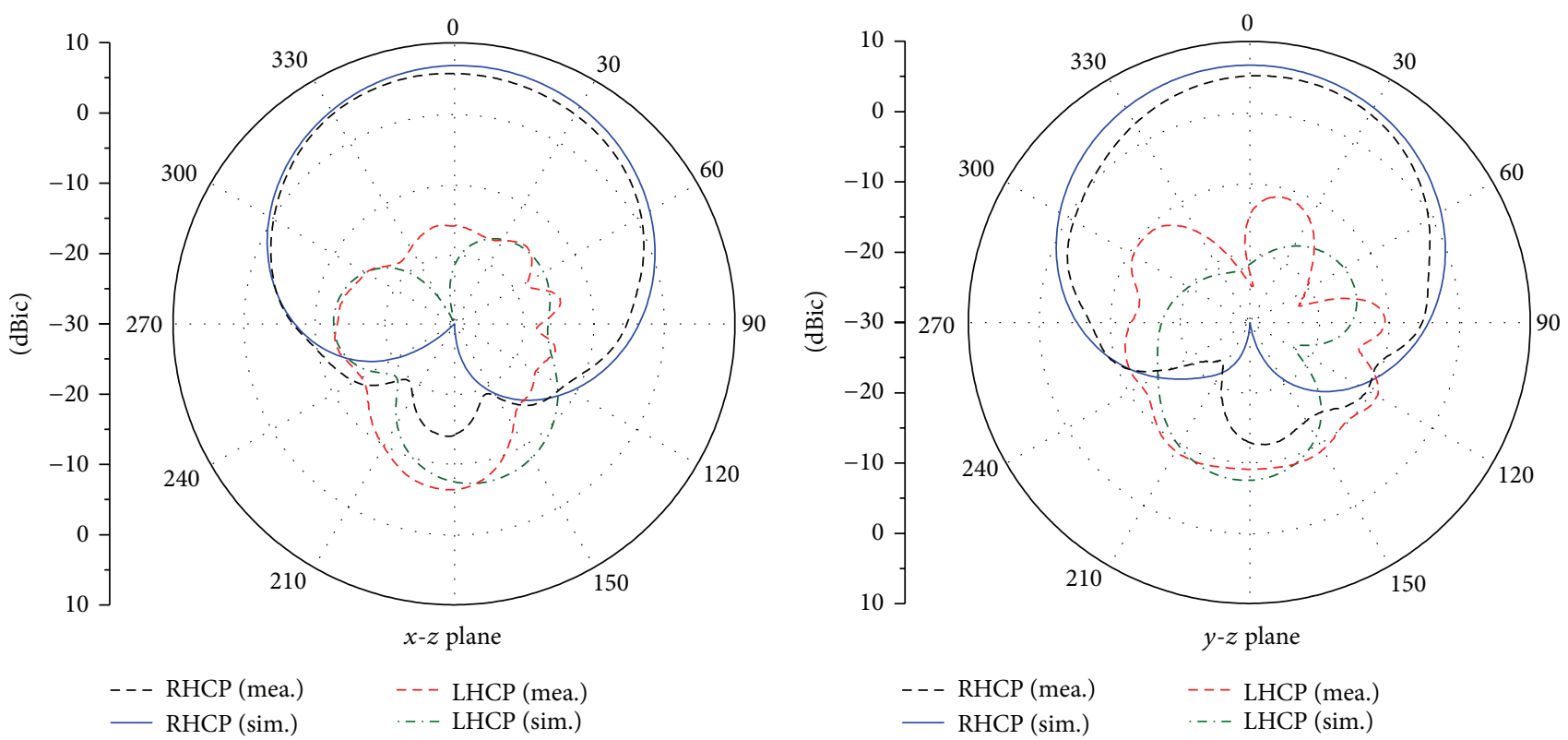

(b)

FIGURE 12: Radiation patterns of the dual-band GPS antenna at (a) GPS L1 and (b) GPS L2 frequencies. 


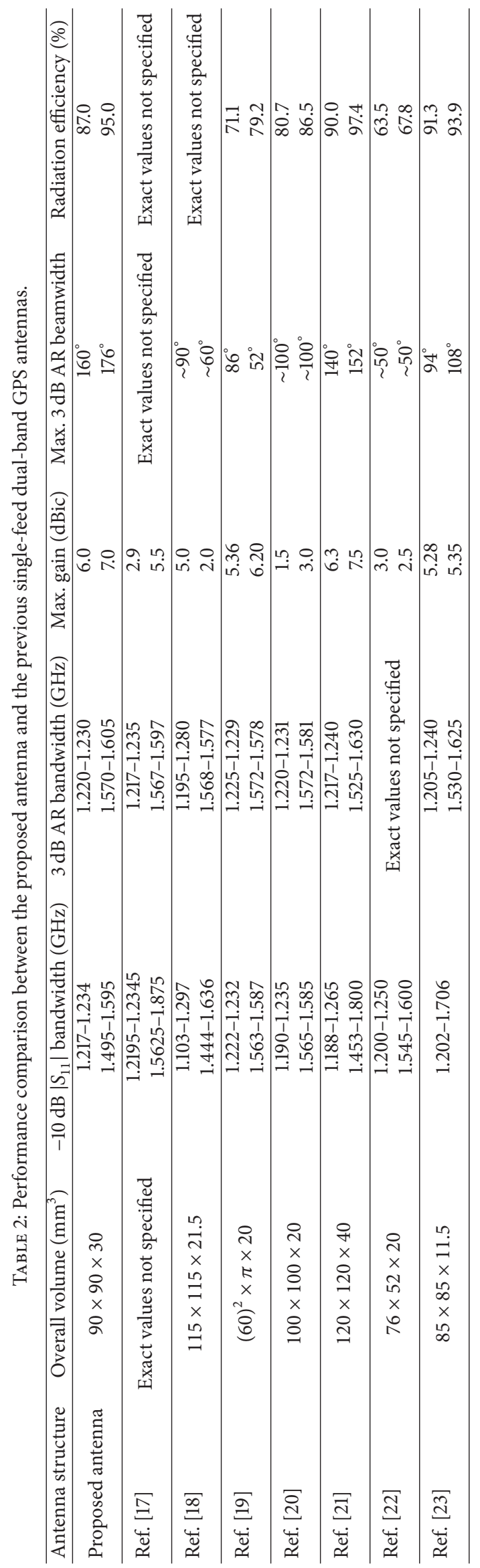






(a)

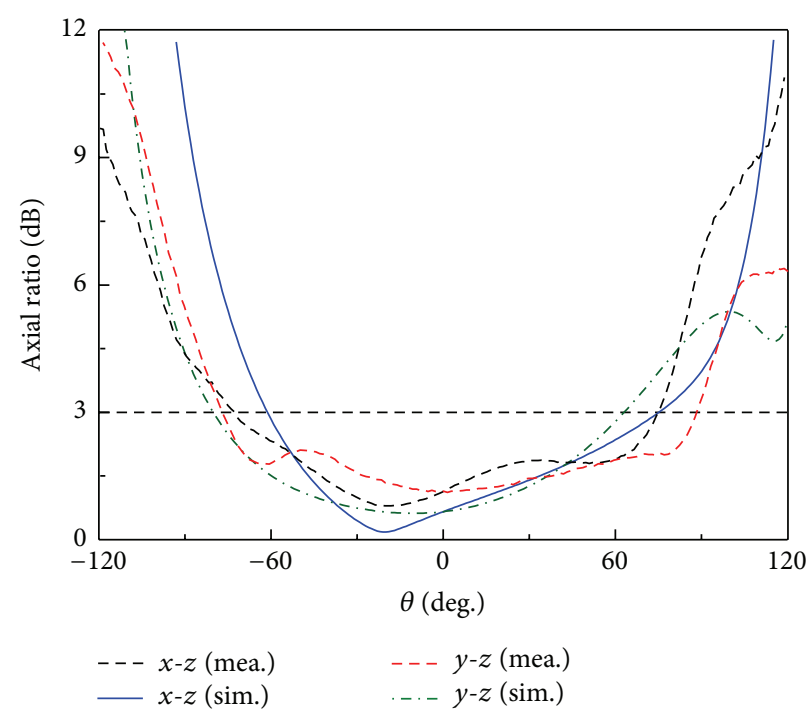

(b)

FIGURE 13: Axial ratio as a function of theta angle: (a) GPS L1 and (b) GPS L2 frequencies.

candidate for dual-band applications with a small frequency ratio.

\section{Conflict of Interests}

The authors declare that there is no conflict of interests regarding the publication of this paper.

\section{Acknowledgment}

This work was also supported by the National Research Foundation of Korea (NRF) Grant funded by the Korea Government (MSIP) [no. 2009-0083512].

\section{References}

[1] H. Nakano, S. Okuzawa, K. Ohishi, H. Mimaki, and J. Yamauchi, "A curl antenna," IEEE Transactions on Antennas and Propagation, vol. 41, no. 11, pp. 1570-1575, 1993.

[2] H. Nakano and H. Mimaki, "Axial ratio of a curl antenna," in Proceedings of the IEE Proceedings Microwaves, Antennas and Propagation, vol. 144, no. 6, pp. 488-490, December 1997.

[3] H. Nakano, M. Yamazaki, and J. Yamauchi, "Electromagnetically coupled curl antenna," Electronics Letters, vol. 33, no. 12, pp. 1003-1004, 1997.

[4] S. M. O'Kane and V. F. Fusco, "Constrained wire curl antenna design for minimum axial ratio," in Proceedings of the $3 \mathrm{rd}$ European Conference on Antennas and Propagation, pp. 33183321, March 2009.

[5] S. M. O'Kane and V. F. Fusco, "High gain curl antenna CP lens," in Proceedings of the 3rd European Conference on Antennas and Propagation (EuCAP '09), pp. 3118-3120, Berlin, Germany, March 2009.

[6] S. M. O'Kane and V. F. Fusco, "Circularly polarized curl antenna lens with manual tilt properties," IEEE Transactions on Antennas and Propagation, vol. 57, no. 12, pp. 3984-3987, 2009.
[7] H. Nakano, S. Kirita, N. Mizobe, and J. Yamauchi, "Externalexcitation curl antenna," IEEE Transactions on Antennas and Propagation, vol. 59, no. 11, pp. 3969-3977, 2011.

[8] S. H. Zainud-Deen, M. M. Badaway, H. A. Malhat, and K. H. Awadalla, "Circularly polarized plasma curl antenna for 2.45 $\mathrm{GHz}$ portable RFID reader," in Proceedings of the 31st National Radio Science Conference (NRSC '14), pp. 1-8, Cairo, Egypt, April 2014.

[9] F. Yang and Y. Rahmat-Samii, "A low-profile circularly polarized curl antenna over an electromagnetic band-gap (EBG) surface," Microwave and Optical Technology Letters, vol. 31, no. 4, pp. 264-267, 2001.

[10] P. Raumonen, M. Keskilammi, L. Sydanheimo, and M. Kivikoski, "A very low profile CP EBG antenna for RFID reader," in Proceedings of the IEEE Antennas and Propagation Society International Symposium, vol. 4, pp. 3808-3811, Monterey, Calif, USA, June 2004.

[11] J.-M. Baracco, M. Paquay, and P. de Maagt, "An electromagnetic bandgap curl antenna for phased array applications," IEEE Transactions on Antennas and Propagation, vol. 53, no. 1, pp. 173-180, 2005.

[12] H. Farahani, F. Fereidoony, M. Veysi, E. Soufiani, and A. Khaleghi, "A low-profile, wideband circularly polarized curl antenna backed by a polarization dependent reflector," in Proceedings of the 5th European Conference on Antennas and Propagation (EUCAP '11), pp. 1085-1088, Rome, Italy, April 2011.

[13] S. X. Ta and I. Park, "Single-feed four-arm curl antenna for circularly polarized radiation," in Proceedings of the IEEE International Conference on Computational Electromagnetics (ICCEM '15), pp. 232-234, Hong Kong, China, Feburary 2015.

[14] S. X. Ta and I. Park, "Single-feed composite cavity-backed fourarm curl antenna," Journal of Electromagnetic Engineering and Science, vol. 14, no. 4, pp. 360-366, 2014.

[15] S. X. Ta and I. Park, "A multi-arm curl antenna for GPS applications," Journal of Electromagnetic Waves and Applications, vol. 29, no. 1, pp. 80-91, 2015.

[16] HFSS, High Frequency Structure Simulator Based on the Finite Element Method, Version 13.0, Ansoft Corporation, 2011. 
[17] S. Chen, G. Liu, X. Chen, T. Lin, X. Liu, and Z. Duan, "Compact dual-band GPS microstrip antenna using multilayer LTCC substrate," IEEE Antennas and Wireless Propagation Letters, vol. 9, pp. 421-423, 2010.

[18] Nasimuddin, Z. N. Chen, and X. Qing, "Dual-band circularly polarized S-shaped slotted patch antenna with a small frequency-ratio," IEEE Transactions on Antennas and Propagation, vol. 58, no. 6, pp. 2112-2115, 2010.

[19] P. Jin and R. W. Ziolkowski, "Multi-frequency, linear and circular polarized, metamaterial-inspired, near-field resonant parasitic antennas," IEEE Transactions on Antennas and Propagation, vol. 59, no. 5, pp. 1446-1459, 2011.

[20] W.-T. Hsieh, T.-H. Chang, and J.-F. Kiang, "Dual-band circularly polarized cavity-backed annular slot antenna for GPS receiver," IEEE Transactions on Antennas and Propagation, vol. 60, no. 4, pp. 2076-2080, 2012.

[21] S. X. Ta, I. Park, and R. W. Ziolkowski, "Dual-band widebeam crossed asymmetric dipole antenna for GPS applications," Electronics Letters, vol. 48, no. 25, pp. 1580-1581, 2012.

[22] G. Liu, L. Xu, and Y. Wang, "Modified dual-band stacked circularly polarized microstrip antenna," International Journal of Antennas and Propagation, vol. 2013, Article ID 382958, 5 pages, 2013.

[23] S. X. Ta and I. Park, "Dual-band operation of a circularly polarized radiator on a finite artificial magnetic conductor surface," Journal of Electromagnetic Waves and Applications, vol. 28, no. 7, pp. 880-892, 2014. 




\section{Enfincering}
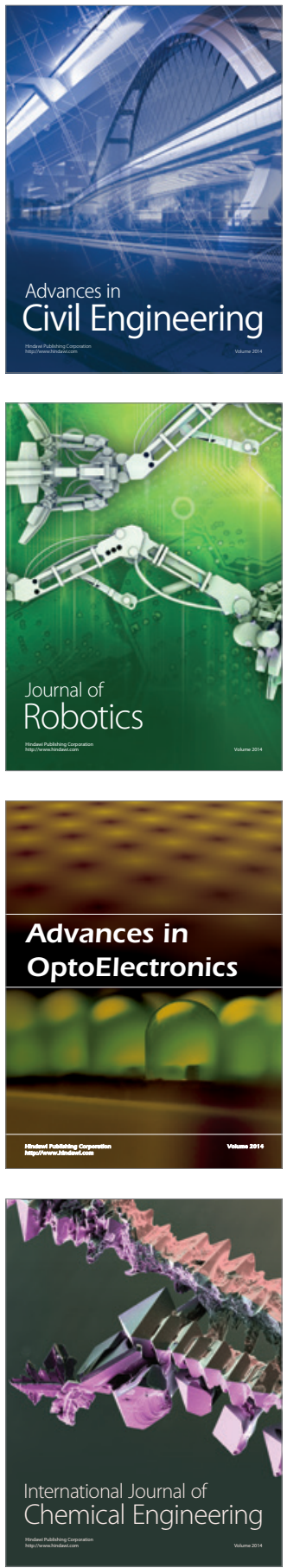



The Scientific World Journal

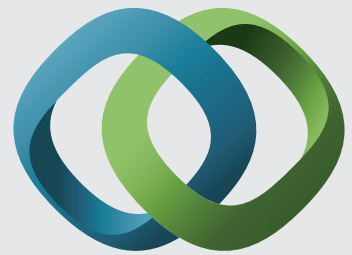

\section{Hindawi}

Submit your manuscripts at

http://www.hindawi.com
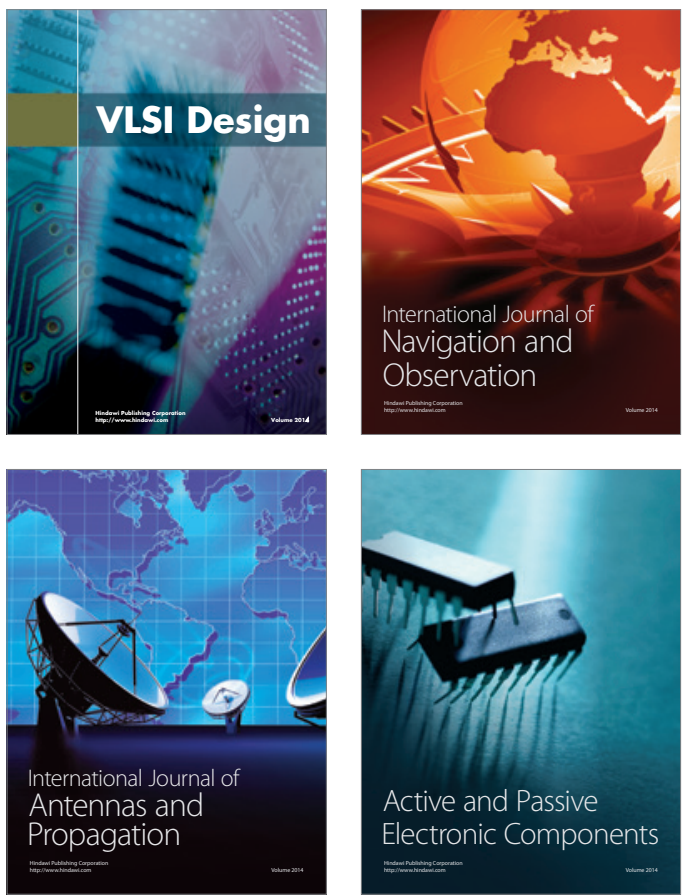
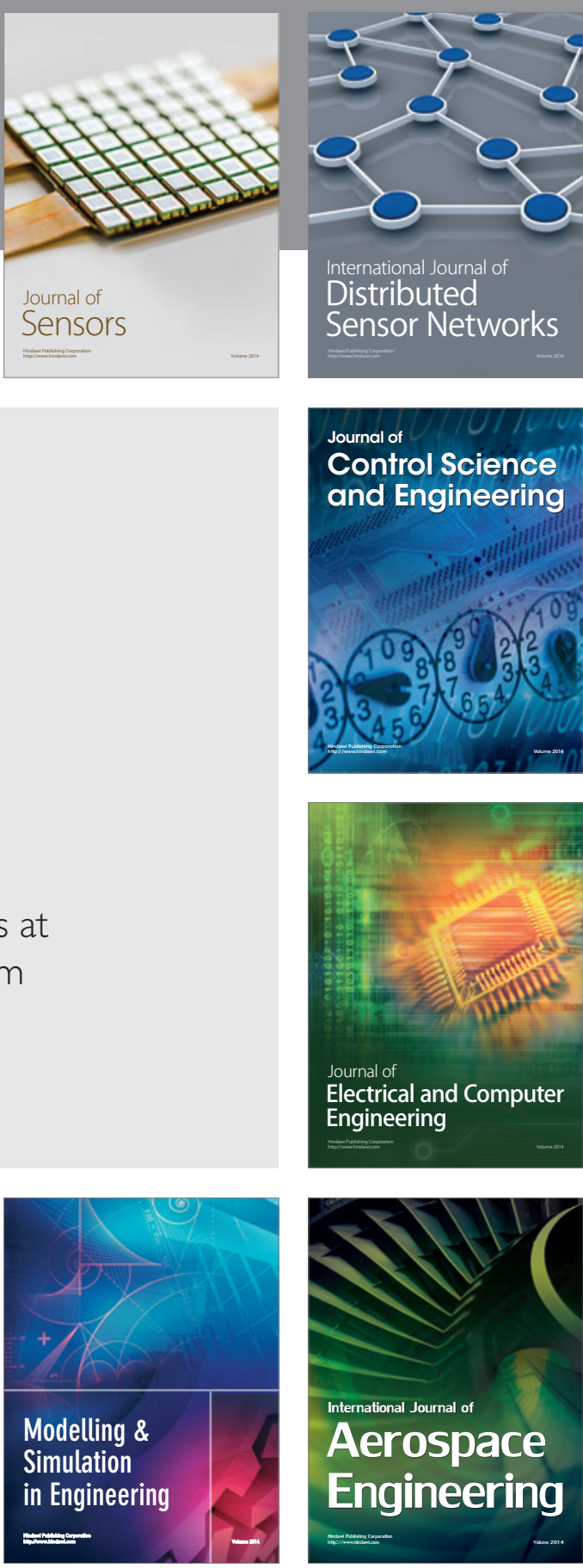

International Journal of

Distributed

Sensor Networks

Journal of

Control Science

and Engineering
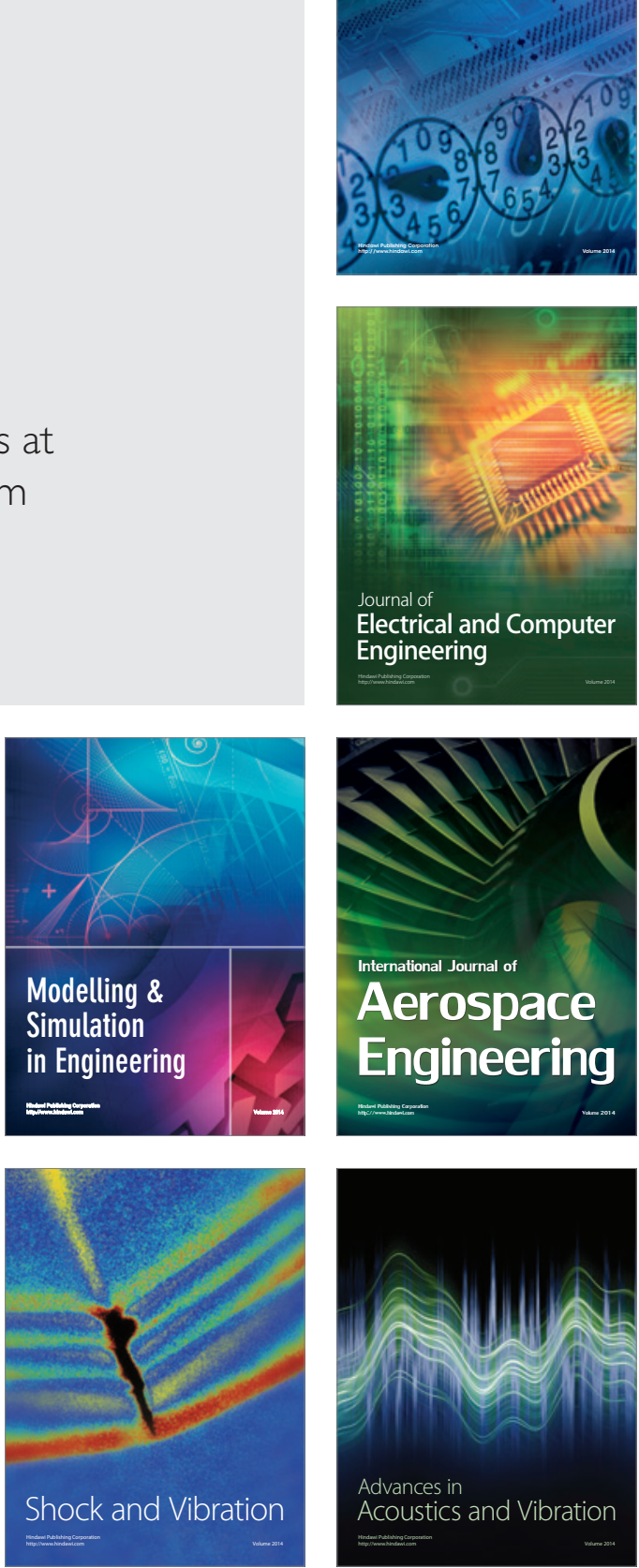